\title{
Investigation of Heat Impact Behavior on Exterior Wall Surface of Building Material at Urban City Area
}

\author{
Mohd Fadhil Md Din ${ }^{1}$, Hazlini Dzinun ${ }^{1 *}$, Ponraj Mohanadoss ${ }^{1}$, Shreshivadasan Chelliapan ${ }^{1}, Z^{2}$ ainura Zainun Noor ${ }^{1}$, Dilshan Remaz Ossen ${ }^{2}$ \\ and Kenzo Iwao ${ }^{3}$
}

${ }^{1}$ Institute of Environmental Water Resources and Management (IPASA), Faculty of Civil Engineering, Universiti Teknologi Malaysia, 81310 UTM Skudai, Johor, Malaysia ${ }^{2}$ Faculty of Built Environment, Universiti Teknologi Malaysia, 81310 UTM Skudai, Johor, Malaysia

${ }^{3}$ Nagoya Institute of Technology, Gokiso-cho, Showa-ku, Nagoya, Aichi-Pref., 466-8555, Japan

\begin{abstract}
This paper represents a comparative study aiming to investigate the heat impact on the vertical surfaces of buildings temperature based on their thermal behaviors. This study was carried out based on four building materials commonly used in Malaysia namely brick, concrete, granite and white concrete tiles. In order to investigate the thermal performance on the building materials, surface temperature sensors, data logging system as well as infrared thermography procedures were used, respectively. As the thermal impact to the materials was measured using infrared thermometric and thermographic, a field work of thermal value can be simply observed as a "seeing heat" effect. The results indicate that bricks had the capability to absorb and store heat greater than other materials during peak daytime event. The normalized (total heat/solar radiation) of brick materials was 0.093 , which was the highest value compared to others. A brick material shows the highest impact of heat in $51 \%$ than white granite material and it releases a substantial amount of heat into the atmosphere through radiation and convection factors. The types of material used at exterior wall buildings have significant impact to the surrounding environment. The use of suitable materials contributes to the reduction of the air temperature due to heat transfer phenomena.
\end{abstract}

Keywords: Thermograph; Building materials; Exterior wall surfaces; Surface temperature; Urban Heat Island (UHI)

\section{Introduction}

The high concentration of hard surfaces actually triggered many environmental issues. The primary root of heat island in cities is due to the absorption of solar radiation by mass building structures, roads, and other hard surfaces during daytime. The absorbed heat is subsequently re-radiated to the surroundings and increases ambient temperatures at night [1]. The use of appropriate materials to reduce heat island and to improve the thermal characteristics of the urban environment has gained increasing interest during recent years. Many research works have been carried out to evaluate the possible energy and environmental benefits, when light colored surfaces are used [2]. Furthermore, some other researchers tried to investigate the impact of the optical materials and thermal characteristics on the urban temperatures as well as the possible energy conservation from heat stroke during the midday.

The heat-retaining properties of building materials, roads, and other surfaces (e.g. asphalt, concrete) contribute to the formation of a phenomenon known as "urban heat island (UHI)" effect. The urban heat island effect is a phenomenon where air temperature in densely built cities is higher than the suburban rural areas. Some of the most important factors which may influence the UHI effect include canyon geometry, thermal properties of materials, anthropogenic heat, the urban greenhouse effect and evaporation surfaces [3]. The maximum UHI intensity usually occurs 3 to $4 \mathrm{~h}$ after sunset in the urban area [4]. Some of the radiation reflected from these surfaces leaves the urban environment much of it is intercepted and partially absorbed by other urban surfaces. As a result cities tend to have lower effective albedo than its surroundings.

In this study, the effect of construction materials that contribute for the UHI and the thermal behavior of different materials used in the vertical buildings of surfaces was investigated. Infrared thermograph was used as a technique for the detection of the thermal performance of the selected buildings. The surface temperature in various types of building materials in Johor Bahru, Malaysia were analyzed during peak sunshine and over brighthess condition. No such study has been conducted in this area previously. This study mainly focused on a comparison between different thermal behavior of four building materials which are commonly applied in Johor Bahru city, such as brick, granite, white concrete tiles and concrete (Figure 1) and thermal properties in (Table 1). The following factors were analyzed including type of building material, different height of vertical buildings and impact of materials used towards outdoor environment. This study can be used to increase the awareness of urban planners, designers and decision makers on the importance of the construction material choices, which is not only for their esthetical aspect but their effect on local climate and indirectly on energy consumption of buildings.

\section{Principles of the Thermal Heat}

In a typical observation, building wall is affected by all three heat transfer mechanisms; conduction, convection, and radiation. The incoming of solar radiation into the outer wall surface will be converted to heat by absorption and transmitted into the building by conduction. In this research, the study focused on the outer surface of building. Therefore, heat of radiation and convection were considered. Total heat can be described as submission of heat of radiation $\left(\mathrm{q}_{\text {rad }}\right)$ and heat of convection ( $\mathrm{q}_{\text {conv }}$ ) as stated below:

Total heat $=\mathrm{q}_{\text {rad }}+\mathrm{q}_{\text {conv }}$

where total heat, $\mathrm{q}_{\text {rad }}$ and $\mathrm{q}_{\text {conv }}$ in $\mathrm{W} / \mathrm{m}^{2}$. The convection and

*Corresponding author: Hazlini Dzinun, Institute of Environmental Water Resources and Management (IPASA), Faculty of Civil Engineering, Universiti Teknologi Malaysia, 81310 UTM Skudai, Johor, Malaysia, Tel: +60 75535130 ; Fax: +60 7 5531575; E-mail: hazlinidzinun@gmail.com

Received January 20, 2012; Accepted February 23, 2012; Published February 25, 2012

Citation: Md Din MF, Dzinun H, Ponraj M, Chelliapan S, Noor ZZ, et al. (2012) Investigation of Thermal Effect on Exterior Wall Surface of Building Material at Urban City Area. J Civil Environment Engg 2:110. doi:10.4172/2165-784X.1000110

Copyright: () 2012 Md Din MF, et al. This is an open-access article distributed under the terms of the Creative Commons Attribution License, which permits unrestricted use, distribution, and reproduction in any medium, provided the original author and source are credited. 


\begin{tabular}{|l|l|l|l|l|}
\hline Location & $\begin{array}{l}\text { Type of material in vertical } \\
\text { surfaces }\end{array}$ & $\begin{array}{l}\text { Density }(\mathrm{kg} \\
\left.\mathrm{m}^{-3}\right)\end{array}$ & $\begin{array}{l}\text { Specific heat }\left(\mathrm{J} \mathrm{kg}^{-1}\right. \\
\left.\mathrm{K}^{-1}\right)\end{array}$ & $\begin{array}{l}\text { Thermal conductivity }\left(\mathrm{W} \mathrm{m}^{-1}\right. \\
\left.\mathrm{K}^{-1}\right)\end{array}$ \\
\hline $\begin{array}{l}\text { (a) Hospital Sultanah } \\
\text { Aminah }\end{array}$ & Brick & 1700 & 800 & 0.84 \\
\hline (b) Tabung Haji & Granite & 2662 & 816 & 0.15 \\
\hline (c) Foh Chong Building & White concrete tiles & 1900 & 800 & 0.31 \\
\hline (d) TJB Building & Concrete (Grey color) & 2300 & 1800 & 0.84 \\
\hline
\end{tabular}

Note: * measurement by spectrophotometer

Table 1: Properties of external surface building materials used.

radiation heat transfer were calculated based on the equations [5]. The outgoing radiation $q^{\prime \prime}$ rad is described by:

$$
q^{{ }^{r a d}}=A \varepsilon \sigma\left(T_{s}^{4}-T_{a}^{4}\right)
$$

where $A=$ Area of the surface material $\left(\mathrm{m}^{2}\right) ; \varepsilon=\operatorname{Infrared}$ emissivity of the surface; $\sigma=$ Stefan-Boltzmann constant $\left(=5.67 \times 10^{-8} \mathrm{Wm}^{-2} \mathrm{~K}^{-4}\right)$; $\mathrm{T}_{\mathrm{s}}=$ Surface temperatures $\left({ }^{\circ} \mathrm{C}\right) ; \mathrm{T}_{\mathrm{a}}=$ Ambient temperatures $\left({ }^{\circ} \mathrm{C}\right)$. The convection heat transfer was calculated using the formula:

$$
q_{\text {conv }}=K_{\text {conv }} A\left(T_{s}-T_{a}\right)
$$

where $A=$ Area of the surface material $\left(\mathrm{m}^{2}\right) ; \mathrm{K}_{\text {conv }}=$ convection heat transfer coefficient $\left(\mathrm{W} / \mathrm{m}^{2} \mathrm{~K}\right) ; \mathrm{T}_{\mathrm{s}}=$ Surface temperatures $\left.{ }^{\circ} \mathrm{C}\right) ; \mathrm{T}_{\mathrm{a}}=$ Ambient temperatures $\left({ }^{\circ} \mathrm{C}\right)[6]$.

Considering heat loss by natural convection, this formula was implemented to account the heat loss due to convection. This formula only considered natural convection under the assumption that the heat loss is caused only by the temperature difference between the surface and its surroundings.

$$
\begin{aligned}
& \mathrm{N}_{\mathrm{GR}}=\left(\mathrm{L}^{3} \rho^{2} \mathrm{~g} \beta \Delta \mathrm{T}\right) / \mu^{2} \\
& \mathrm{~N}_{\mathrm{PR}}=(\mathrm{Cp} \mu) / \mathrm{k}
\end{aligned}
$$

Where $\mathrm{N}_{\mathrm{GR}}$ is the Grashof Number, $\mathrm{L}$ = length in vertical planes (m), $\rho=$ density $\left(\mathrm{kg} / \mathrm{m}^{3}\right), \mathrm{g}=9.80665 \mathrm{~m} / \mathrm{s}^{2}, \beta=$ volumetric coefficient of expansion of fluid $=1 /\left(\mathrm{T}_{\text {film }}\right)=1 /\left(\mathrm{T}_{\mathrm{s}}+\mathrm{T}_{\mathrm{a}}\right)$ in $(\mathrm{K}), \Delta \mathrm{T}=\mid$ positive temperature different between the wall and bulk fluid $(\mathrm{K}), \mu=$ viscosity $(\mathrm{kg} / \mathrm{m} . \mathrm{s}), \mathrm{N}_{\mathrm{PR}}=$ Prandtl Number, $\mathrm{Cp}$ = heat capacity (J/kg.K), $\mathrm{k}=$ thermal conductivity $(\mathrm{W} / \mathrm{m} . \mathrm{K})[6]$.

\section{Methods and Procedure}

\section{Selection of buildings for in-situ measurement}

Four locations have been selected in Johor Bahru area as shown in (Figure 2). The choices of the buildings were determined based on types of material used for construction. As seen in the figure the buildings on the south-orientated of exterior wall building for different materials were investigated.

Hospital Sultanah Aminah (HSA) is geographically located at latitude $1^{\circ} 27^{\prime} 31.64^{\prime \prime}$. North of the Equator and longitude $103^{\circ} 44^{\prime} 46.16^{\prime \prime}$. East of the Prime Meridian where as latitude $1^{\circ} 27^{\prime} 28.98^{\prime \prime}$. North of the Equator and longitude $103^{\circ} 45^{\prime} 33.03^{\prime \prime}$. East of the Prime Meridian is location of Tabung Haji. Foh Chong Building is geographically located at latitude $1^{\circ} 27^{\prime} 22.89^{\prime \prime}$. North of the Equator and longitude $103^{\circ} 45^{\prime}$ $52.61^{\prime \prime}$. East of the Prime Meridian where as latitude (1.4605 degrees) $1^{\circ}$ $27^{\prime} 37^{\prime \prime}$. North of the Equator and longitude (103.7594 degrees) $103^{\circ} 45^{\prime}$ 33". East of the Prime Meridian is location of Menara TJB.

\section{Data logger and solar intensity measurement}

A simple data measurement was taken using thermostats with an accuracy of $\pm 0.5^{\circ} \mathrm{C}$, connected to data logger of non-volatile memory (GRAPHTEC data logger) for the registration of the surface temperature on the references samples. A data logger with temperature and relative humidity sensors were recorded with accuracy of $\pm 0.2^{\circ} \mathrm{C}$ for temperature and 3\% for relative humidity. Solar radiation was measured by a pyranometer types (EKO, MS 602).

\section{Thermal graphic measurement}

The infrared camera was used to capture the 'picture of heat' at building surfaces; in a case of thermal images were recorded at every 2 min from 9:30 AM until 9:00 PM during this study. The type of infrared camera used was ThermaCAM from FLIR Systems with 640 x 480 pixels, full colour and working in the wavelength band of 7.5 to $13 \mu \mathrm{m}$ and a specified accuracy of $\pm 0.2^{\circ} \mathrm{C}$ of reading. These infrared cameras can detect the infrared radiation in the shorter wave length $(3-5 \mu \mathrm{m})$ or in the longer wave length $(8-14 \mu \mathrm{m})$. Shorter wave length cameras are more appropriate for high temperatures while longer wave length ones provide best results at low temperature $\left(0-100^{\circ} \mathrm{C}\right)$. The infrared cameras commonly used in the thermal surveys of buildings are works in the long wave length spectrum because they are more sensitive to lower temperatures (ambient and above), able to detect small temperature differences and less affected by the reflection caused by solar rays.

\section{Data sampling}

The study consists of in-situ temperature measurements on the building surfaces of selected buildings within $3 \mathrm{~km}$ radius around Johor Bahru city in order to measure the UHI phenomena. The study was conducted in various influences of weather and climates; which recorded in a consistent date measurement for 3 month observation begun from June till August 2010. The periodic month is chosen because prolong clear and shiny condition compared to other month in a year. There are some limitations in this study which highly influence by winds that could reduce the effectiveness of outdoor surveys due to surface temperature shear effects. Similarly, rain may also lead to surface cooling, thus masking thermal effects from below the surface.

Information of thermal behaviors' of materials used was examined through the reflectivity, absorption and albedo aspects. A continuous measurement of surface temperature in various construction materials was plotted in graphical forms by using GRAPHTEC data logger.

The experimental equipment consists of temperature sensors which is thermocouple type $\mathrm{T}$, connected to a Graphtec midi data logger. The ambient and surface temperature was recorded in Graphtec midi data logger in every $2 \mathrm{~min}$ from 8:00 in the morning until 19:00 in the evening. The measurements were limited to this range of time, due to safety of the instrument. The temperature sensors were placed on the vertical surfaces of building with $0.5,1.0,1.5$ and $2.0 \mathrm{~m}$ high from ground level.

For surface temperatures, the thermocouples were bonded with epoxy to the surface and covered with cloth construction tape. The thermocouple measuring ambient temperature was protected from solar radiation by a radiation shield. In comparison, the surface 
temperature readings were taken with an Infrared (IR) thermometer and camera thermal image at every $30 \mathrm{~min}$ from 9:30 AM until 9:00 PM throughout a day.

For ambient temperature, the temperature sensors were placed on the vertical surfaces of building with $1 \mathrm{~m}$ away from any building and 1.5 $\mathrm{m}$ high from ground level. For comparison, ambient temperature was also measured using Lutron 4 in 1 Environment Tester (Anemometer, Hygrometer, Light Meter \& Thermometer). The measurement always taken directly exposed to sunlight, $1 \mathrm{~m}$ away from any building and 1.5 $\mathrm{m}$ high from ground level.

The measurements of IR thermometer to the vertical surface material are limited to a height of no more than $3 \mathrm{~m}$, due to restrictions posed by the instrument. On each of the measured external walls, IR readings was measured at different heights, together with different parts of the exterior surfaces with the intention of correlation to the pedestrians' thermal comfort perception, in order to ensure that recorded surface temperature were representative. The ambient (a)

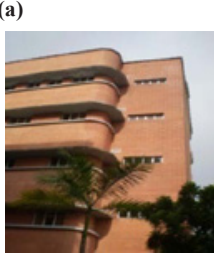

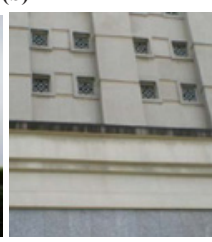

(c)

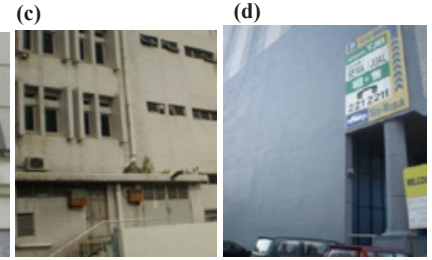

Figure 1: The selected facade buildings in Johor Bahru areas; (a) Hospital Sultanah Aminah, (b) Menara Tabung Haji (c) Foh Chong Building and (d) TJB Building.

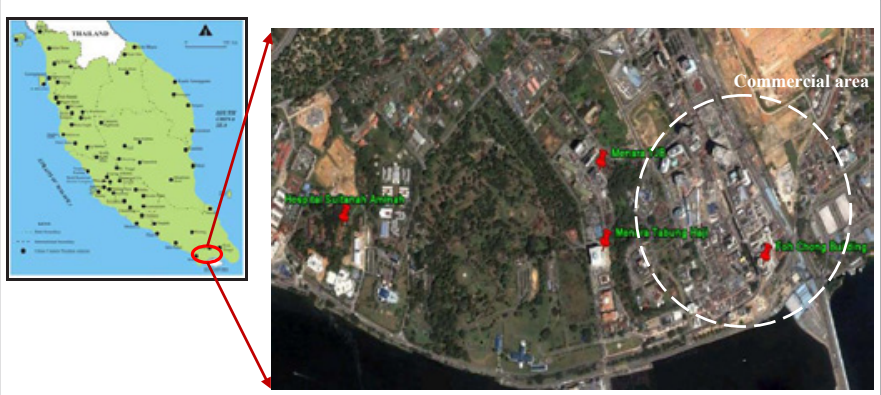

Figure 2: Site selection in Johor Bahru, located in the southern Malaysia.

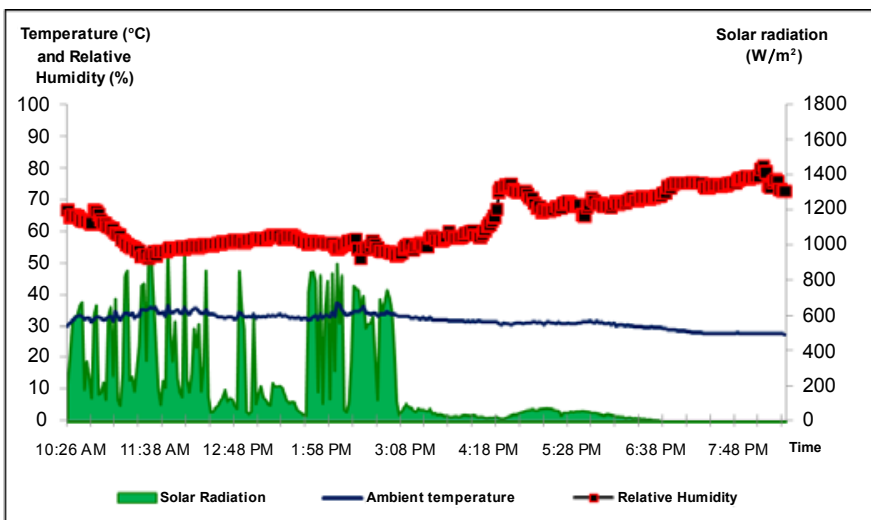

Figure 3: Ambient data record of solar radiation, temperature and relative humidity for Case 1. temperatures, relative humidity and air velocity were then determined using Lutron 4 in 1 Environment Tester (Anemometer, Hygrometer, Light Meter \& Thermometer).

\section{Results}

\section{Analysis of existing exterior building based on different materials}

This part discusses the four locations of the observed study area with a different types of exterior wall building material that most commonly used in Johor Bahru city, namely brick, granite, concrete and white concrete tiles. The impact of materials used and the solar radiation intensity were then analyzed to find out their influence on the outdoor surface temperature of the building.

Case 1-Hospital sultanah aminah: Figure 3 shows the ambient temperature, relative humidity and solar radiation between 10:30 AM until 9:00 pm. The mean wind speed values from data obtained during measurements is $0.63 \mathrm{~m} / \mathrm{s}$, which consider as moderate calm wind profile. The maximum ambient temperature was recorded up to $37.2^{\circ} \mathrm{C}$ at $2: 12 \mathrm{PM}$ and the minimum was depicted at $27.4^{\circ} \mathrm{C}$ at $9: 00$ $\mathrm{pm}$, whereas the mean ambient temperature was recorded at $31.6^{\circ} \mathrm{C}$. The maximum relative humidity was measured at $80.4 \%$, whereas the minimum value and mean relative humidity were reported at $51.2 \%$ and $62.9 \%$ respectively. As shown in Figure 3, solar radiation was fluctuated started from $10.36 \mathrm{AM}$ until $3 \mathrm{pm}$, then it suddenly drops until reached $0 \mathrm{~W} / \mathrm{m}^{2}$ because of the cloudy weather.

The survey carried out during the day (presence of direct solar radiation) succeeded thermal images at different temperatures. Simultaneously, with the infrared camera observation, a sensitive contact thermometer (i.e. shot-gun temperature and thermo couple) was checked twice to ensure the accuracy of the online data logger. Once recorded, a correlation between infrared camera and contact thermometer is determined. From the images captured, a clear zone has been identified, which correspond to the colors' characterization. Lighter colors appeared at lower temperature than darker ones. As showed in the images, the temperature identification of each image is prepared according to the local time and weather.

Surface temperatures at brick wall had reached about $32.5^{\circ} \mathrm{C}$ at 9:30 $\mathrm{AM}$ and their maximum was $7^{\circ} \mathrm{C}$ higher than the ambient temperature. At 12:00 noon, surface temperature rose to $41.1^{\circ} \mathrm{C}$ higher than the ambient air temperature by $9^{\circ} \mathrm{C}$ different. It is due to the storage of solar heat absorbed by the buildings in the previous daytime, as the solar radiation was recorded highest up to $1005.73 \mathrm{~W} / \mathrm{m}^{2}$. Therefore, brick wall was absolutely absorbed more heat due to the heating direct solar radiation during daytime. As shown in the captured images, the brick wall appears in red dark colour.

At 4:30 pm, the solar transmission was lower than recorded at 12:00 noon. As a result, the surface temperatures decrease to $33.4^{\circ} \mathrm{C}$ and steadily reduce by $8^{\circ} \mathrm{C}$ lower than those monitored at 12:00 noon. Surface temperatures of exterior wall building varied during midday due to the heat capacity of brick wall. The temperature difference was caused by their different thermal inertia [7]. The bricks began to increase the temperature faster than the glass material, thus proves that brick had larger capacity to store heat. Furthermore, at midday hotter zones can be observed in the thermal images caused by the overheating due to the effect of solar rays on the building facades, the contrary is also true (see Figure 4).

Case 2-Menara tabung haji: Menara Tabung Haji is a single 


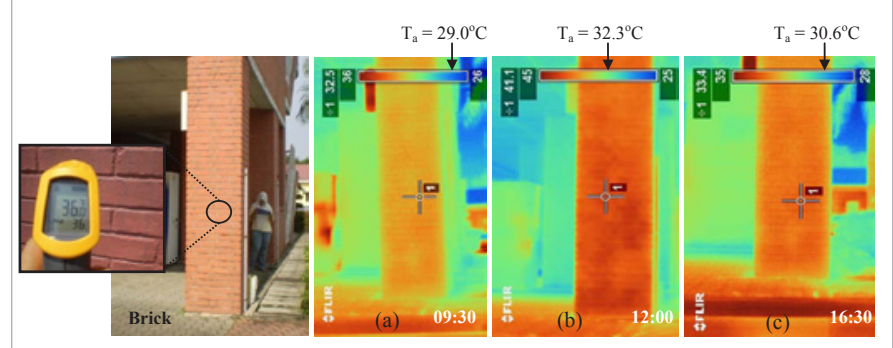

Figure 4: The visible and thermal image of brick wall at different time (a) morning (b) afternoon (c) evening.

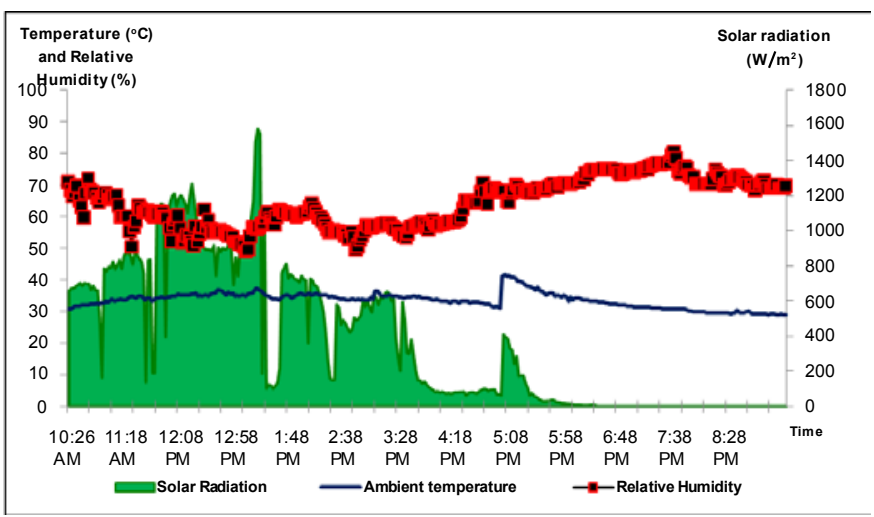

Figure 5: Ambient data record of solar radiation, temperature and relative humidity for Case 2 .

detached-building located in Johor Bahru. Based on the observation, the east-side exterior wall of the building was reached the higher values of solar radiation. Figure 5 shows the ambient temperature, relative humidity and solar radiation at the continuous period from 10:52 AM until 10:00 pm. The highest value of solar radiation was depicted up to $1585.96 \mathrm{~W} / \mathrm{m}^{2}$ (Figure 5). However, since the orientation of exterior wall is not exposed consistently, the direct solar rays only fell upon the samples until 6:00 pm. The mean wind speed values from data obtained during measurements is measured at $1.8 \mathrm{~m} / \mathrm{s}$, which consider as calm condition. The maximum ambient temperature was depicted at $41.7^{\circ} \mathrm{C}$ at 5:39 pm, whereas the minimum value was reported at $29.0^{\circ} \mathrm{C}$ at 9:00 $\mathrm{pm}$. Overall the ambient temperature was observed at $33.5^{\circ} \mathrm{C}$. The maximum relative humidity recorded was $80.4 \%$ with minimum and relative humidity recorded at $48.9 \%$ and $64.3 \%$, respectively.

Figure 6 shows that the colors in the afternoon are relatively intense, while in the evening and morning periods are relatively light. These phenomenons can most likely be attributed to the difference in the angle of the elevation and the intensity of direct solar radiation. As showed in the images, the temperature of each image is prepared according to the local time and weather. Surface temperatures for exterior wall building of Menara Tabung Haji had reached about $31.1^{\circ} \mathrm{C}$ at $11: 00 \mathrm{AM}$ and their maximum was $2^{\circ} \mathrm{C}$ higher than the ambient temperature. As evident, the exterior wall of buildings is just starting to absorb heat because of intensity of solar radiation. At $1: 40 \mathrm{pm}$, surface temperature rose to $41.9^{\circ} \mathrm{C}$ higher than the ambient air temperature by $5^{\circ} \mathrm{C}$ different. It is due to the storage of solar heat absorbed by the buildings in the previous daytime and at this time, the solar radiation was recorded highest at $1585.96 \mathrm{~W} / \mathrm{m}^{2}$ which means that granite absorbs and stores heat from direct solar radiation during daytime. This is obviously shown in the images; in which the granite material appears in dark red colour.

Case 3-Foh chong building: Foh Chong Building is a commercial building located in Johor Bahru. Figure 7 shows the ambient measurement from 9:00 AM until 9:00 pm. The maximum ambient
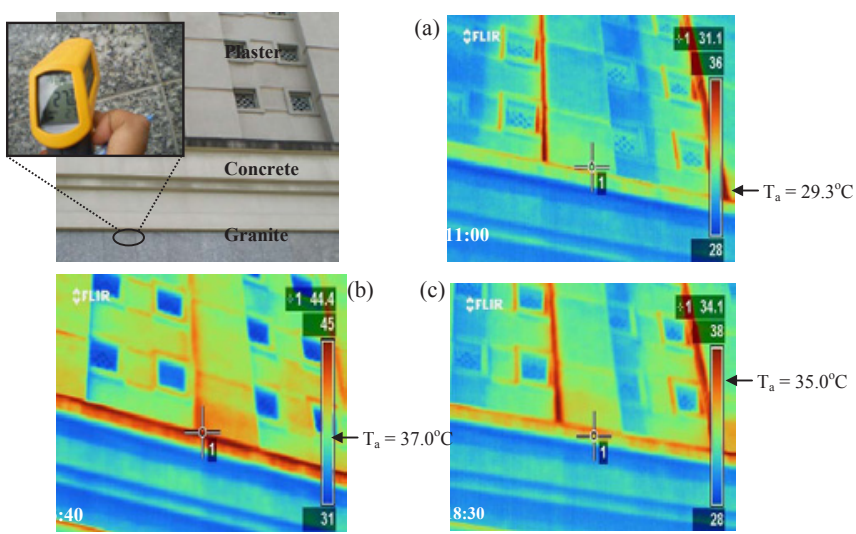

Figure 6: The visible and thermal image of granite at different time (a) morning (b) afternoon (c) evening.

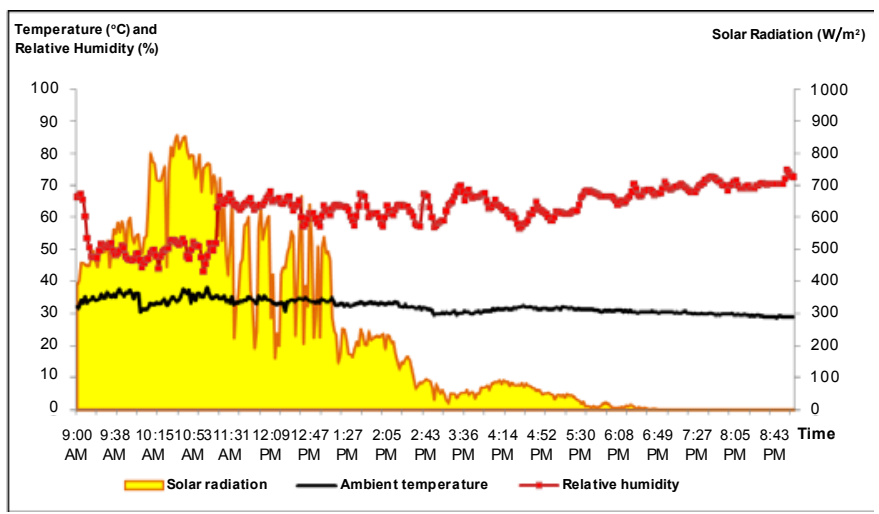

Figure 7: Ambient data record of solar radiation, temperature and relative humidity for Case 3 .
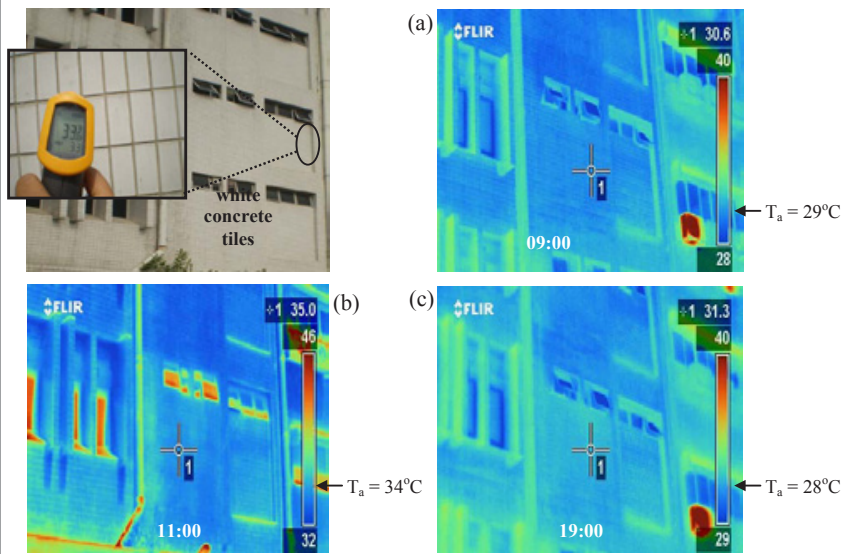

Figure 8: The visible and thermal image of wall tiles at different time (a) morning (b) afternoon and (c) evening. 
temperature was recorded up to $38.1^{\circ} \mathrm{C}$ at $11: 07 \mathrm{am}$, the minimum was determined at $28.8^{\circ} \mathrm{C}$ at $8: 45 \mathrm{PM}$ and the mean ambient temperature was depicted at $32.2^{\circ} \mathrm{C}$. The maximum relative humidity was $74.9 \%$ with its minimum and mean value at $43.1 \%$ and $62.2 \%$, respectively. The highest value of solar radiation was monitored at $859.6 \mathrm{~W} / \mathrm{m}^{2}$. Unfortunately, the direct solar rays fell upon the samples only recorded until 5:40 pm.

Thermography offers the possibility of obtaining a map of the surface temperatures of an object as shown in Figure 8. The scale of temperature had been changed according to the maximum and minimum values of temperature during the observation day. Surface temperatures for exterior wall building of Foh Chong Building had reached about $37.7^{\circ} \mathrm{C}$ at 11:00 $\mathrm{AM}$ and the maximum was up to $3^{\circ} \mathrm{C}$ higher than the ambient temperature. At 7:00 pm, the surface temperature was dropped and close to the air temperature. Parts of the area on the exterior surface are identified as 'blue' color. This showed that the exterior wall building is a "cool" material. From the temperature measurement, the wall tiles has least absorb any heat from the solar radiation showing the dynamic behavior of the surface material chosen. Based on material properties, the heat capacity of white concrete tiles is relatively low; heat from the daytime solar radiation can be prevented to store. Therefore, the incoming solar radiation has been reflected accordingly and it can cause energy balance at the surfaces.

Case 4-TJB building: TJB Building is a commercial building located in an urban region of Johor. The building is constructed of reinforced concrete and the east-side exterior surface of the building reached the higher values of solar radiation. Figure 9 shows the ambient temperature, relative humidity and solar radiation as monitored from 10:40 AM until 8:30 pm. The mean wind speed is recorded around 0.7 $\mathrm{m} / \mathrm{s}$. The highest value of solar radiation was recorded up to $1025.79 \mathrm{~W} /$ $\mathrm{m}^{2}$, however the direct solar rays was only measurable until 6:19 pm. The maximum ambient temperature was recorded at $35.1^{\circ} \mathrm{C}$ at $2: 54 \mathrm{PM}$ with minimum and mean value at $30.0^{\circ} \mathrm{C}$ and $32.3^{\circ} \mathrm{C}$, respectively. The maximum relative humidity was recorded at $73.9 \%$ with its minimum and mean value depicted at $56.1 \%$ and $63.5 \%$, respectively.

From the obtained thermal images, it can be observed that the concrete structure was preferably storing heat. It showed in Figure 10 , part of the area in the exterior surface material shows a red dark color, even the direct solar radiation is gone at $5.00 \mathrm{pm}$. The red areas in thermograph occur because the external surface of the building was exposed directly to the solar radiant without any sun-shading. The temperature was higher than the air temperature due to the direct solar radiation during the daytime. The surface temperatures for exterior wall building had reached about $31.5^{\circ} \mathrm{C}$ at $11: 00 \mathrm{AM}$ and their maximum was $1.5^{\circ} \mathrm{C}$ higher than the ambient temperature. At this time, the exterior walls of the buildings were just starting to absorb heat because the solar radiation had started falling into the buildings. This can be seen at 2:30 PM where part of the area in the facade surface showed a red dark color which indicated a high temperature. The red areas in the thermograph occurred on external surfaces of the building because there was no protection from the sun. The temperatures in those areas were higher than the ambient temperature due to the heat from direct solar radiation. The temperature of the concrete that was warmer than the surrounding concrete was shown in yellowish color. These characteristics showed that the wall has a capability to store heat. Although the surface temperature of these areas rose slightly in the late afternoon, the surface temperature fell and was close to the air temperature at sunset. At 5:00 $\mathrm{pm}$, the surface temperature reduced to $33.9^{\circ} \mathrm{C}$; higher than the ambient air temperature by $3^{\circ} \mathrm{C}$.

\section{Analysis of sensible heat flux mechanism}

The heat gain from within the exterior surface buildings is governed by their physical characteristics and of materials used. The heat exchanges that occur on exterior wall buildings are more intense between their external surfaces and their environment. As closer the surface temperature is to the air temperature, as lower is the transmission of heat to the environment by convection and by radiation [8]. In order to calculate the heat flux over the entire surface of the building, the ambient temperature and surface area of each element of the entire building were measured, respectively. The total heat, convection and radiation heat were calculated based on the equations stated in equation (1), (2) and (3) respectively.

It seems that the calculations for heat of radiation and convection are made based on the differences shown between surface and ambient temperature, accordingly for the current experiment the trend change in terms of heat flux intensity of convection and radiation for corresponding temperature changes measured are shown in Figure 11. It is obvious that if there is no difference between surface and ambient temperature, the heat of convection (q'conv) and heat of radiation (q'rad) the subsequent emission to the atmosphere will be significantly low. The values of Figure 11 (a) and (b) indicates that the values of heat of radiation are greater than the values of heat of convection and clearly shows that the heat flux of exterior surface changes smoothly due to the nature of thermal properties of wall materials.

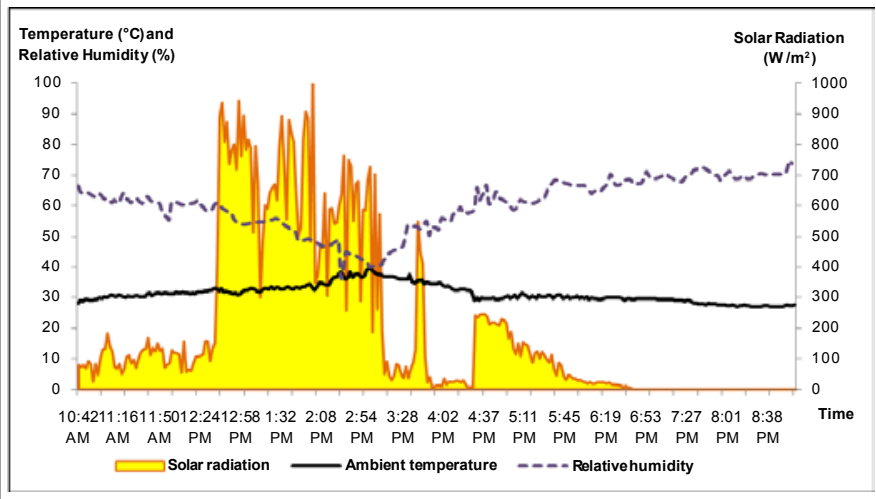

Figure 9: Weather data for Case 4
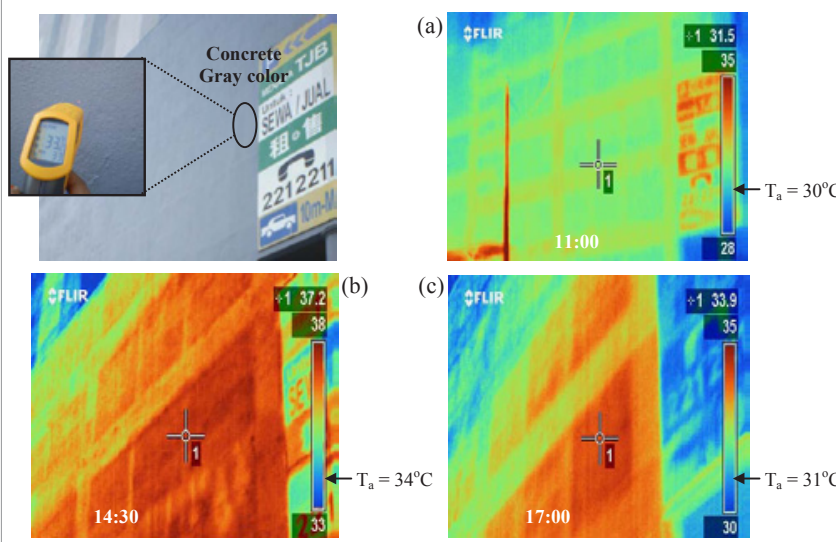

Figure 10: The visible and thermal image of concrete wall at different time (a) morning (b) afternoon and (c) evening. 
The convection and radiation of heat transfer also depends on the intensity of solar radiation falling towards the exterior wall buildings. The comparison between these four materials cannot be made because of each buildings have different conditions of experimental measurement and it influenced via the values of convection and radiation heat transfer. Therefore, in order to determine the suitable materials at exterior wall building, the normalized of each material were calculated and analyzed as shown in Figure 12.

Figure 12 represents the normalized (total heat/Sr) which is defined as heat of convection plus heat of radiation and divided by average of solar radiation. Total heat indicated that the amount of heat would increase the ambient temperature as well as make contribution to the UHI impact. The normalized (total heat/Sr) of brick materials was 0.093 ,
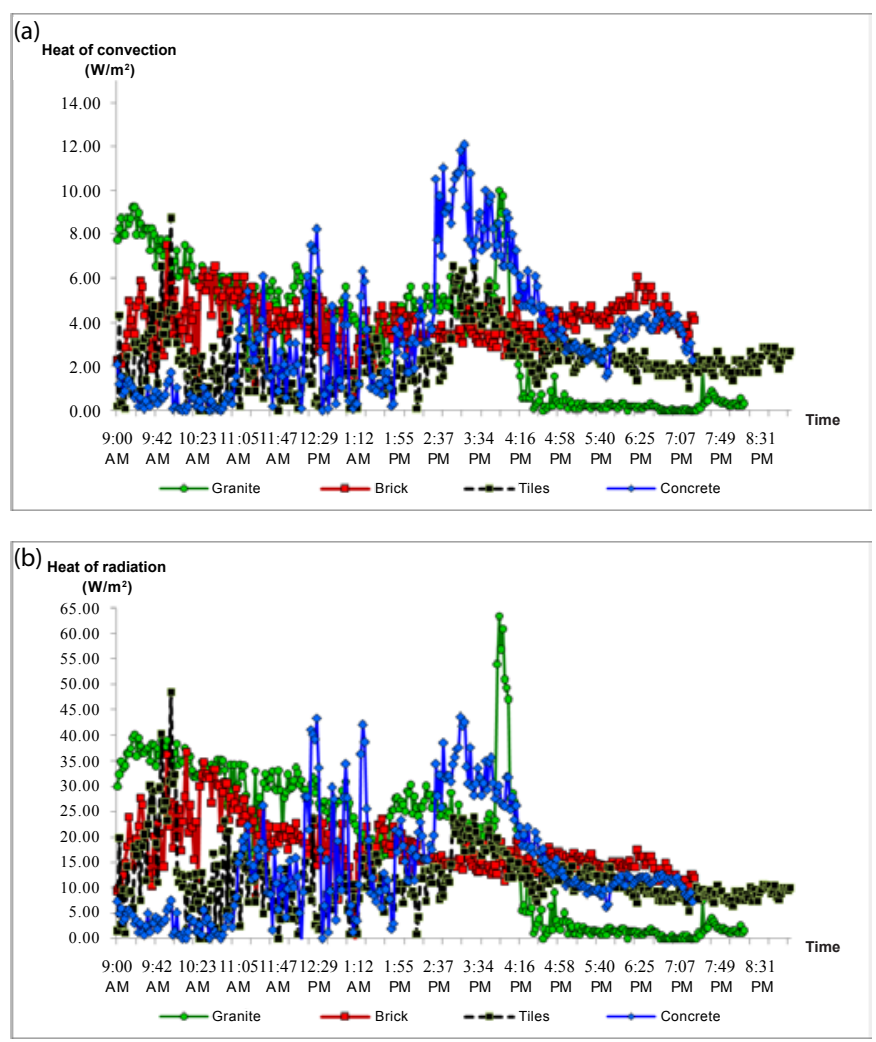

Figure 11: (a) Heat of convection and (b) Heat of radiation for different materials.

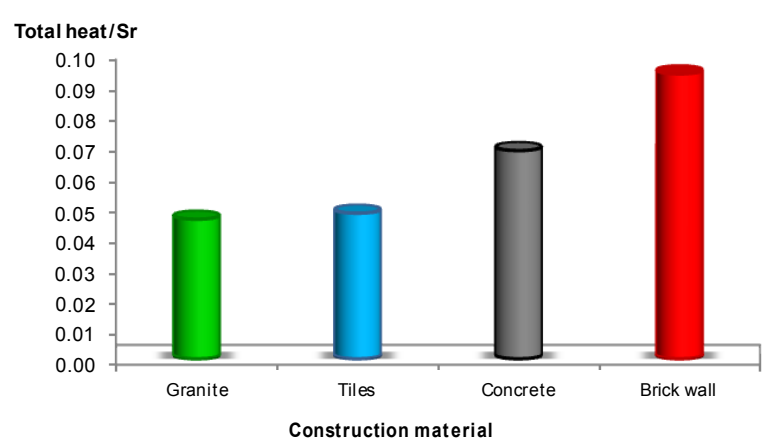

Figure 12: Normalized of (total heat/solar radiation) using average heat of convection (qconv), heat of radiation (qrad) and solar radiation ( $\mathrm{Sr}$ ). which was the highest value compared to others. Brick materials show the highest impact of heat in 51\% than granite material and it releases a substantial amount of heat into the atmosphere through radiation and convection. The normalized for granite and white concrete tiles have relatively the same. This was expected due to the values of specific heat for both materials are relatively the same.

It can be expected that the capacity of heat stored in different material was the main influence contribution to the UHI impact. For example, brick material is the evident of increment surrounding area because of its capacity of storing heat energy. The absorbed heat will be released back to the surrounding environment and warm up the ambient near the material surfaces throughout the day. This was because the energy accumulated within the exterior wall during midday and was released during the night time in the form of heat. This is actually the root of the urban heat island effect in the built environment [9]

\section{Conclusion}

In this study, the applications of IR thermograph for the detection of different thermal behavior of two buildings were presented. The different types of material illustrated the different heat impact on the surrounding environment. Thus, by referring to the final result, the most sensitive of absorb and storing heat are recorded as follows; brick $>$ concrete $>$ granite and white concrete tiles. As a conclusion, granite and white concrete tiles are suitable material for the exterior wall building; providing a thermally comfortable for outdoor environment, while can contribute highly to improve the urban microclimate mainly for UHI phenomena. The results from this research could provide valuable information to the thermographer whose work is concerned with the making up of urban buildings.

\section{Acknowledgement}

The authors wish to thank Dr Mohd Fadhil Md Din, Dr Remaz Dilshah Ossen and $\mathrm{Dr}$ Zainura Zainun Noor for their valuable help and support, Mr Salleh for his technical help in using infrared thermographic and also to Dr Ponraj for the final checking of the manuscript. The authors are also grateful to Professor Kenzo Iwao at Nagoya Institute Technology, Japan for his useful advice and instrumentation supplied to do this research. Our sincere gratitude goes to Universiti Teknolog Malaysia and Academic Science Malaysia for their financial supports under the Fundamental Research Grant Scheme (No. 4F041).

\section{References}

1. Chow WTL, Roth $M$ (2006) Temporal dynamics of the urban heat island of Singapore. Int J Clim 26: 2243-2260.

2. Doulos L, Santamouris M, Livada I (2004) Passive cooling of outdoor urban spaces. The role of materials. Solar Energy 7: 231-249.

3. Dzinun H, Md Din MF, Noor ZZ, Iwao K, Chellapan S (2010) Analysis of hea impacted behavior at vertical façade building based on heat flux mechanism. Proceedings of 2010. International Conference on Environment and Industria Innovation (ICEII 2011) IACSIT Press, Singapore 7: 74-78.

4. Guerrero IC, Ocana SM, Requena IG (2005) Thermal-physical aspects of materials used for the construction of rural buildings in Soria (Spain). Construction and Building Materials 19: 197-211.

5. Ocana SM, Guerrero IC, Requena IG (2004) Thermographic survey of two rural buildings in Spain. Energy and Buildings 36: 515-523.

6. Prado RTA, Ferreira FL (2005) Measurement of albedo and analysis of its influence the surface temperature of building roof materials. Energy and Buildings 37: 295-300

7. Santamouris M (2001) Energy and climate in the urban built environment James \& James Science Publishers, London.

8. Wong NH, Chen Y (2009) Tropical Urban Heat Islands: Climate, buildings and greenery. Taylor \& Francis Group, London and New York.

9. Wong NH, Chena Y, Ongb CL, Siab A (2005) Investigation of thermal benefits of rooftop garden in the tropical environment. Building and Environment 38 : 261-270. 